Yu. N. LINNIK ${ }^{1}$, Professor, Doctor of Engineering Sciences

V. Yu. LINNIK ${ }^{1}$, Associate Professor, Doctor of Economic Sciences, vy_linnik@guu.ru

A. B. ZHABIN 2 , Professor, Doctor of Engineering Sciences

A. V. POLYAKOV', Professor, Doctor of Engineering Sciences, Academic Counselor of the Academy of Mining Sciences

${ }^{1}$ State University of Management, Moscow, Russia

${ }^{2}$ Tula State University, Tula, Russia

\title{
THEORETICAL FRAMEWORK FOR THE EFFICIENCY EVALUATION OF COAL MINING MACHINES
}

\begin{abstract}
Introduction
The operating practice of coal mining machines shows [1-4] that their efficiency, especially in cutting complex structure coal seams of high cuttability in many ways depends on whether the cutter head design meets operating conditions, as well as economical [5], technological and engineering constraints $[6,7]$. In this respect, designers need tools to calculate the load spectrum of a cutter head in different operating conditions of mining different cuttability coal. The load spectrum governs the limit torque of transmission mechanism, allowable torsion torque with regard to durability of transmission gears etc., i.e., the determinants of the above-listed constraints. First of all, it is necessary to determine structure and properties of coal seams, estimable using an aggregate index of equivalent coal cuttability $A_{\text {eqv }}[8,9]$, and to find mechanisms of their effect on pick failure.

Theoretical evaluation of production of energy resources is demandable to ensure sustainable fuel supply to power generating plants [9]. By now, Russian thermal power stations produce $17.9 \%$ of heat and electric energy [10]. Thus, it is critical to create theoretical framework for the optimal design of picks and cutter heads of coal mining machines to ensure required capacity of production faces in specific geological conditions.
\end{abstract}

\section{Coal mining machine capacity}

The main economic efficiency criterion of a mining machine is the theoretical (estimated) capacity $\left(Q_{\mathrm{t}}, \mathrm{t} / \mathrm{min}\right)$ given by:

$Q_{\mathrm{t}}=B_{\mathrm{ww}} H_{\mathrm{mt}} V_{\text {fr }} \gamma_{\text {coal }}, \mathrm{t} / \mathrm{min}$, where $B_{w w}$ is the web width, $\mathrm{m} ; H_{\mathrm{mt}}$ is the mineable thickness of coal seam, $\mathrm{m} ; V_{\mathrm{ft}}$ is the feed rate, $\mathrm{m} / \mathrm{min} ; \gamma_{\text {coal }}$ is the density of coal, $\mathrm{t} / \mathrm{m}^{3}$.

In this manner, the theoretical capacity is directly proportional to the mining machine feed rate in specific operating conditions. The feed rate is directly proportional to the depth of cut which is a key index of the cutter head efficiency. Thus, theoretical capacity of a mining machine is governed by the efficiency (capacity) of the cutter head of the machine.

Efficiency of a shearer is most often evaluated as a relation between the total intake power $P_{\Sigma}$ and the capacity $Q_{t}$ in the specific conditions of coal structure and cuttability assessed in aggregate by the index $A_{\text {eqv }}(\mathrm{N} / \mathrm{mm})$ :

$$
P_{\Sigma}=f Q_{\mathrm{t}} \text { (at } A_{\text {eqv }}=\text { const). }
$$

The dependence of the type of (2) has been in use for a long time [11, 12]. At the known operating conditions of cutter head and characteristics of the medium to be cut, this relation defines the required power as a function of the preset capacity of a mining machine. Vice versa, at the known operating conditions of a mining machine, its elements (e.g., torque of cutting drive unit) or units of a longwall system (advance of support, capacity of armored face conveyor, etc.), this relation determines potential capacity in the preset conditions:

$$
Q_{\mathrm{t}}=f\left(A_{\text {eqv }}\right)
$$

The dependence of the type of (3) is an operation constraint of a mining machine as a function of the coal cuttability $A_{\text {eqv }}$. For shearer (the most complex case against the plowing machines), all possible operation constraints are divided into three groups: economical, technological and engineering constraints. The economical constraints are the most essential: minimal allowable (economically expedient) capacity, allowable grade, replacement conditions of tools. These constraints (1E-3E in Fig. 1) and the analogous constraints (dust generation, energy intake) define the minimal capacity below which the use of the given machine model is assumed as unprofitable (lower bound of possible operation conditions for mining machines). Usually, these constraints are given by: $Q_{\mathrm{t}} \geq Q_{\mathrm{t} \text {.all }}$ (where $Q_{\mathrm{t} \text {.all }}$ is the allowable capacity) and indirectly depend on $A_{\text {eqv }}$. 
The technological constraints include the rate of feed, capacities of coal haulage machines and roof support, gas criterion and permanent output of motor (since the cycle duration and the motor duty cycle are governed by the operating condition of the longwall system) [13]. The technological constraints usually define the wanted upper bound of productivity (1T-3T in Fig. 1), i.e., $Q_{\mathrm{t}} \geq Q_{\mathrm{t} \text {.tech }}$ (where $Q_{\mathrm{t} \text {.tech }}$ is the theoretical capacity with regard to the technological constraints).

Alongside with $A_{\text {eqv }}$ independence of the most constraints, there permanent output relation $P_{\text {perm }}=f\left(A_{\text {eqv }}\right)$ nonlinearly bounds (4T in Fig. 1) the possible productivity field from the right.

The engineering (design) constrains are the most essential and governed by the shearer design. These constraints first of all relate the maximal rate of feed, pulling power of feed assembly, allowable overhang of picks, maximal torque in the conditions of actual power supply at proper output* (1D-4D in Fig. 1). The methods to determine these engineering constraints are in detail reviewed in [9]. The pulling power constraint and the maximal torque constraint (stable output) depend on coal breaking characteristics and should be evaluated in aggregate using the equivalent cuttability index $A_{\text {eqv }}$, which, unlike the previous cutting resistance index $A_{\text {cut }}$, stronger describes cutting dynamics in complex structure coal seams containing large solid inclusions and hard dirt bands.

These constraints, in the aggregate, shape a system of productivity constraints shown in Fig. $\mathbf{1}$ in the coordinates $Q_{t}\left(V_{\text {ir }}\right)-A_{\text {eqv. }}$. The efficient productivity domain of shearer lies inside the field of possible operating conditions abcd (Fig. 1). The operating conditions which fit the points inside this field are allowable for a given machine with regard to all three groups of constraints. The line $b c$ characterizes the application range of the mining machine with respect to the index $A_{\text {eqv }}$, and the point $c$ shows the allowable application domain.

According to the analysis [14], the constrains that govern potential productivity are, as a rule, the engineering constraints of the pulling power (for shearers to mine coal seams with a thickness more than $3 \mathrm{~m}$ and a dip angle more than $15^{\circ}$ ), moment (thin coal seams) or heat (heavy duty longwalling) of motors. The research shows [15] that the capacity of mining machines with a high power-to-weight ratio is also limited by durability of the drive elements as an increase in the drive capacity (at the same size, materials and gearing) results in a considerable decrease in the safety factor of the transmission elements subjected to higher loading.

The quantitative estimate of the influence exerted by the coal seam structure on the coal strength characteristics is also required as the latter govern, alongside with the other factors, the dynamic load of the mining machine motor $[7,8,11$, 16-18].

When a mining machine operates different capacity motors at the same time, the operation is constrained by the limiting moment tolerable by the strength of the transmission elements.

In the general case, this constraint is given by:

$M_{\text {max }}=M_{\mathrm{av}}+M_{\mathrm{dyn}} \leq M_{\mathrm{all}}$,

where $M_{\max }$ and $M_{\text {all }}$ are the current allowable maximal moments in transmission to cutter head, respectively; $M_{\mathrm{av}}$ is the average moment; $M_{\text {dyn }}$ is the dynamic moment.

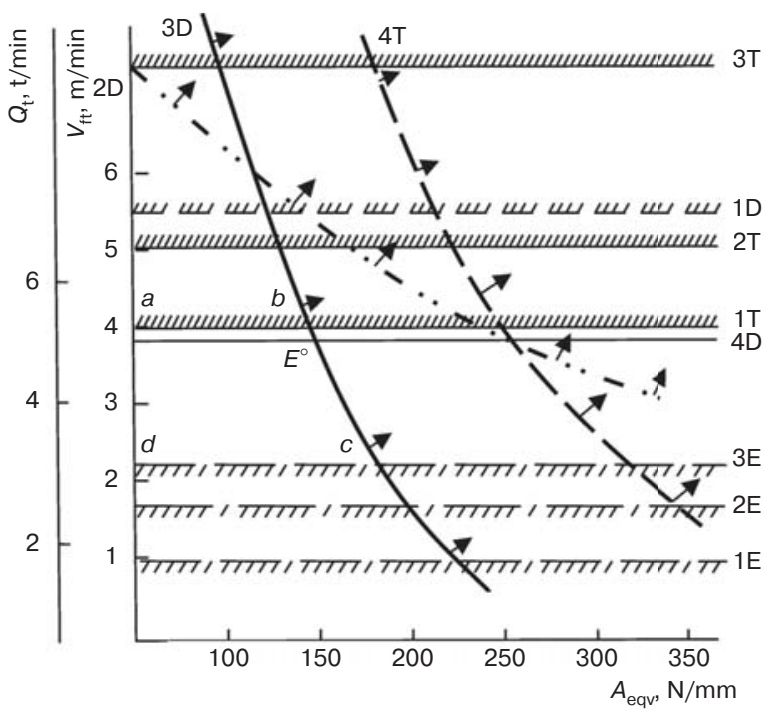

Fig. 1. Mining machine operation constraints: Economical cutting tool replacement conditions (1E), minimum capacity (2E), allowable coal grade (E3); Technological - support capacity (1T), coal haulage capacity (2T), gas criterion (3T), permanent output of motor (4T); Engineering (Design) maximal feed rate of shearer (1D), pulling force of feed assembly (2D), maximal (stable) moment (3D), radial overhang of pick (4D)

The current maximal moment:

$$
M_{\text {max }}=\left(F_{\text {ch }}+Z_{\text {pick }}\left(1+3 v_{\text {zpick }}\right)\right) D_{\mathrm{ch}} / 2, \mathrm{~N} \cdot \mathrm{m} \text {, }
$$

where $F_{\mathrm{ch}}$ is the total cutting force of cutter head, $\mathrm{N} ; Z_{\text {pick }}$ is the maximal average-pick cutting force of pick, $\mathrm{N} ; \mathrm{v}_{z \text { pick }}$ is the variation factor of the average-pick cutting force; $D_{c h}$ is the diameter of the cutter head, $m$.

Using (4) and (5) allows the unknown constrain to be given by:

$$
F_{\text {ch.all }} \leq\left(2 M_{\text {all }} / D_{\text {ch }}\right)-Z_{\text {pick }}\left(1+3 v_{\text {zpick }}\right) \text {, }
$$

where $F_{\text {ch.all }}$ is the allowable circumferencial force of the cutter head with respect to the strength of the transmission elements.

It is necessary to introduce the durability constraint of the most loaded element of transmission (usually, gear). The authors propose a relation to evaluate the allowable average torsion torque $M_{\mathrm{tt} \text {.all }}$ to agree with the equivalent moment in the strength design at the safety factor of 1 in case of the varying loading of the transmission:

$$
M_{\mathrm{tt} \text {.all }}=\frac{M_{\mathrm{eqv}} K_{\mathrm{SF}}^{2}\left(1-v_{\mathrm{tr}}^{2,4}\right)^{3}}{m_{\text {eqv }}} \sqrt[3]{\frac{T_{\mathrm{d}}}{T_{\mathrm{r}}}},
$$

where $M_{\text {eqv }}$ and $K_{\mathrm{SF}}$ are, respectively, the estimated equivalent moment and safety factor of the highest loaded transmission gear; $v_{\mathrm{tr}}$ is the variation factor of loads; $m_{\text {eqv }}$ is the coefficient of equivalence; $T_{\mathrm{d}}$ and $T_{\mathrm{r}}$ are the design and estimated durabilities, respectively:

$$
v_{\mathrm{tr}}=\sqrt{v_{1 i}^{2}+K_{\mathrm{gain}}^{2}\left(v_{2 i}^{2}+v_{3 i}^{2}\right)+v_{4 i}^{2}+v_{5 i}^{2}},
$$

where $v_{1 i}, v_{4 i}, v_{5 i}$ are the low-frequency components of the load variation factor; $K_{\text {gain }}$ is the gain constant; $v_{2 i}, v_{3 i}$ are the highfrequency components of the load variation factor. 

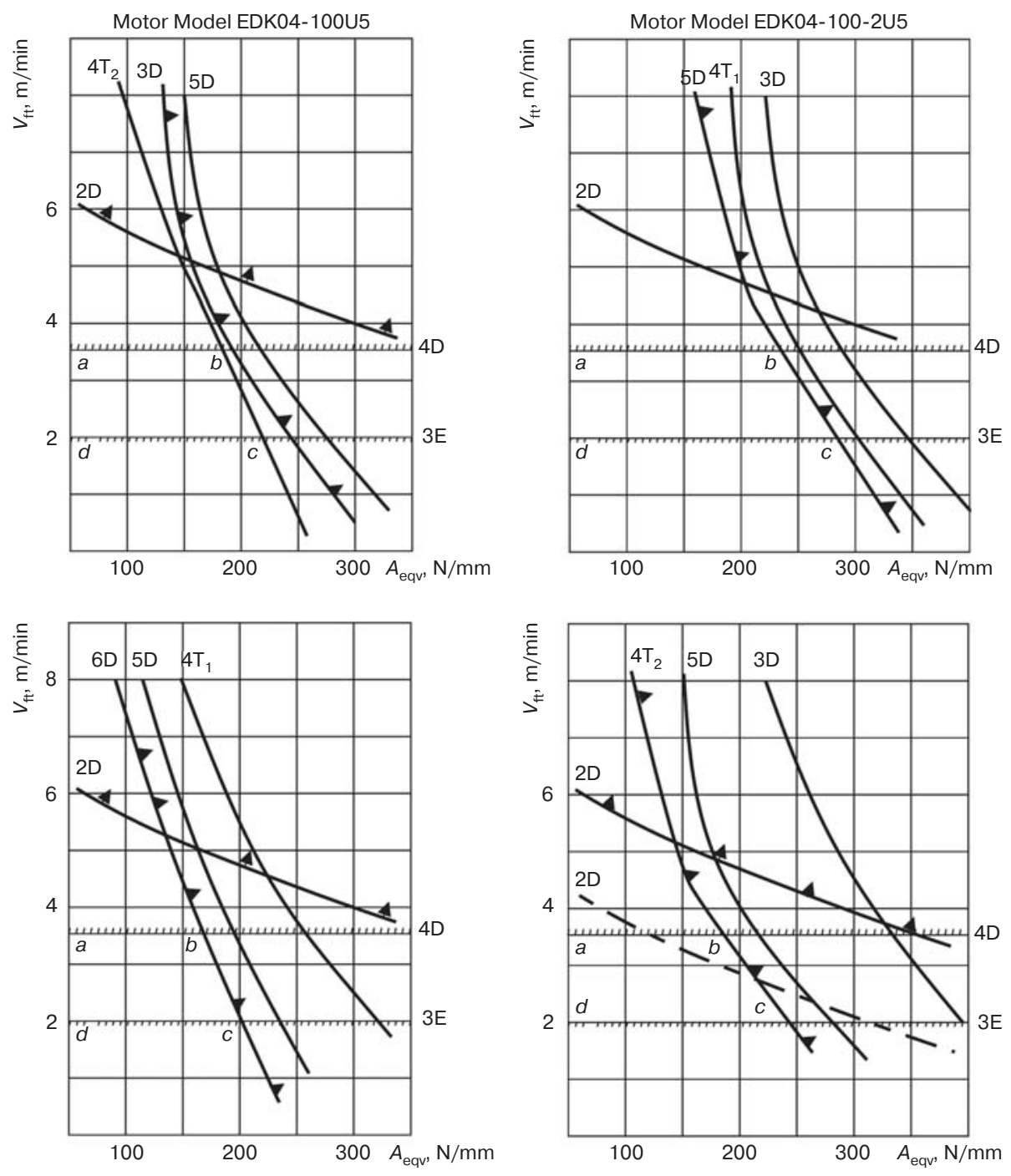

Fig. 2. Potential productivity and efficient application domains of shearer at different constraints: Design constraints - pulling power (2D), maximal (stable) moment (3D), rate of feed (4D), durability of the highest loaded element of transmission (5D), durability of motor (6D); Technological constraints - continuous power at duty cycle of 25 and $40 \%\left(4 T_{1}\right.$ and $4 \mathrm{~T}_{2}$, respectively); Economical constraints - allowable grade of coal (3E)

It follows from the formula (8) that the load spectrum on the cutter head is currently treated as a sum of independent low-frequency $\left(v_{1 i}, v_{4 i}, v_{5 i}\right)$ and high-frequency $\left(v_{2 i}, v_{3 i}\right)$ components governed by:

(a) The design features, namely, different number of picks engaged and, thus, different average cutting force on the cutter head. The design variation factor is determined from the expression:

$$
v_{1 i}=\frac{1}{F_{\mathrm{av}}} \sqrt{\frac{1}{k} \sum_{j=1}^{k}\left(F_{\mathrm{av}_{j}}-F_{\mathrm{av}}\right)^{2}},
$$

where $F_{\text {av }}$ is the average total cutting force on the cutter head; $F_{\mathrm{av}_{j}}$ is the cutting force at a $j$-th position of the cutter head; $k$ is the number of the positions (assumed as $k \geq 32$ ).

(b) The brittle behavior of coal in fracture, described by the nonuniform (saw-like) form of the force diagram of a pick. In view of the actual arrangement of picks, the load variation factor of the cutter head is found from the formula:

$$
v_{2 i}=v_{z} \sqrt{\sum_{i=1}^{n_{c}}\left(\frac{Z_{i}}{F_{\text {avmin }}}\right)^{2}},
$$

where $Z_{i}$ is the cutting force on each of $i$ picks engaged in cutting, $\mathrm{N} ; n_{\mathrm{c}}$ is the number of picks on the cutter head; $F_{\text {avmin }}$ is the minimum average value of the total cutting force on the cutter head.
The variation factor $v_{z}$ of the cutting force on a pick is assumed as $0.5-1.2$ depending on the coal seam structure.

(c) The varied cuttability $A_{\text {eqv }}$ of coal in the section cut with the cutter head, which, together with the influence of the pick arrangement pattern on the cutter head, induces variation in load:

$$
v_{3 i}=v_{A C} \sqrt{\sum_{i=1}^{n_{c}}\left(\frac{Z_{i}}{F_{\text {avmin }}}\right)^{2}} .
$$

The coefficient $v_{A C}$ of cuttability variability in the transverse cross-section of coal face ranges from 0.47 at $A_{\text {eqv }}<$ $<120 \mathrm{~N} / \mathrm{mm}$ to 0.3 at $A_{\text {eqv }}>300 \mathrm{~N} / \mathrm{mm}$.

(d) The varied cuttability $A_{\text {eqv }}$ along the length of longwall, which causes low-frequency variation in load. The values of $v_{4 i}$ range between 0.24 at $A_{\text {eqv }}<120 \mathrm{~N} / \mathrm{mm}$ and 0.12 at $A_{\text {eqv }}>$ $>120 \mathrm{~N} / \mathrm{mm}$.

(e) The varied loading due to nonuniform travel of shearer (plower). The variation factor $v_{5 i}$ (variation limit $0.35-0.05$ ) grows with an increasing average load, lowers with an increasing rate of feed and linearly depends on the feed stiffness.

Figure 2 shows the efficient operation zones for shearers with different capacity motors.

It is seen from the figure that efficient operation (maximal possible productivity) is governed by various constraints: 
- maximal (stable) moment in the same structure seams and using motors with maximal test moments $M_{\text {max.t }}<$ $<180$ dyne/m (Fig. 2a);

- durability of cutting drive motor in complex structure seams (groups 2 and 3 ) and using motors with $M_{\text {max.t }}<$ $<180$ dyne/m (Fig. 2b);

- durability of the cutting drive transmission elements (at any coal breaking characteristics) and using motor with $M_{\text {max.t }}>180$ dyne/m (Fig. 1c);

- allowable continuous (heat) power for shearers with motors of any capacity at duty cycle $>40 \%$ (in high output longwalls) (Fig. 2d).

In coal seams with a dip more than $20^{\circ}$, it is possible that the line $b c$ turns into a broken line eg (Fig. 2d) under the impact of the feed assembly puling power constraint.

The operating modes inside or at the boundary of the field abed (aegcd) meet all constraints. The line bc in this case is the line of efficient operation at the highest productivity.

The governing factors of the efficient use of cutter heads are:

- the increase in face output through the increased productivity (feed rate) of mining machine owing to the reduced energy input of fracture at the full-scale utilization of the installed drive capacity;

- the increase in face output through the higher working capacity (cutting time ratio) as a result of shortened period of pick replacement and improved attachment of picks to cutter head;

- the adjustment of the electric energy cost with increasing (decreasing) energy consumed in mining;

- the adjustment of cutter head cost with increasing (decreasing) reliability and price;

- the decrease (worsening) of produced coal grade.

These factors should be considered as the direct sources of efficiency depending on the specificity of design and use of cutter heads.

The governing factors are interconnected. For the first turn, productivity depends on reliability of cutter heads. The actual practice shows that sometime intensification of cutting by means of mining machines with higher power-to-weight ratio produces no anticipated gain in productivity due to insufficient reliability of shearers and plowers and, first of all, their cutter heads. Design of mining machines lacks as a rule the highest efficiency in terms of coal grade and energy intake in favor of reliability of cutter heads and transmissions.

\section{Conclusion}

The studies prove that efficiency evaluation of cutter heads is a complex multi-criterion problem requiring data on operating conditions, cutting mode, loads and reliability of mining machines and their components.

References

1. Gubenko A. A., Klementeva I. N. Impact of technological, kinematic and force parameters on technical performance miner. Nauchnyi vestnik Moskovskogo gosudarstvennogo gornogo universiteta. 2011. No. 2. pp. 23-27.

2. Elenkin V. F., Klementeva I. N. Peculiarities of the Cutter-loader Screw Interaction with a Coal Bed within a Friction Contact Zones. Ugol. 2012. No. 9. pp. 40-42.

3. Khoreshok A. A., Tsekhin A. M., Borisov A. Yu. Influencing of Operation Conditions of Mining Machines on the Design of their Effectors. Gornoe oborudovanie i elektromekhanika. 2012. No. 6. pp. $2-5$.
4. Linnik Yu. N., Zhabin A. B., Linnik V. Yu., Polyakov A. V. Notes about how cutters and cutterholders malfunctions affect to indicators of coal-plow machines work efficiency. Izvestiya Tulskogo gosudarstvennogo universiteta. Nauki o Zemle. 2018. No. 2. pp. 247-263.

5. Verbitskaya G. L. Improvement of the method of optimization of innovative risks at mining enterprises under uncertainty. Nauchnyi vestnik natsionalnogo gornogo universiteta. 2017. No. 3. pp 114-121.

6. Demin V. F., Nemova N. A., Demina T. V., Zeytinova Sh. B. Controlover geomechanical processes intended to impruve a coal-and-rock massif stability. Nauchnyi vestnik natsionalnogo gornogo universiteta. 2016. No. 2. pp. 5-10.

7. Nechitaylo Yu. A., Bazhinova T. A., Veselaya M. A. The energy estimation of transportation vehic. Nauchnyi vestnik natsionalnogo gornogo universiteta. 2016. No. 6. pp. 84-88.

8. Linnik Yu. N., Sherstkin V. V., Linnik V. Yu. Integral criterion of coal seam breakability. Gornyi Zhurnal. 2015. No. 8. pp. 37-41. DOI: 10.17580/gzh.2015.08.09

9. Linnik Yu. N., Linnik V. Yu. Information System for Underground Coal Mining Output Prediction. Upravlenie. 2014. Vol. 2, No. 3. pp. 23-27.

10. Gibadullin A. A., Gilts N. E., Romanova Ju. A., Romanova Ir. N., Bahretdinova Kh. A. The development strategy of the environmental safety of the electric power complex. IOP Conference Series: Materials Science and Engineering. 2019. Vol. 537, No. 4. 042065. DOI: 10.1088/1757-899X/537/4/042065

11. Morkovkin D. E., Gibadullin A. A., Romanova Ju. A., Erygin Yu. V., Ziadullaev UI. S. Formation of a national environmental strategy for the fuel and energy complex. IOP Conference Series: Materials Science and Engineering. 2019. Vol. 537, No. 4. 042064. DOI: 10.1088/1757-899X/537/4/042064

12. Pozin E. Z., Melamed V. Z., Ton V. V. Coal cutting by shearers. Moscow : Nedra, 1984. $286 \mathrm{p}$

13. Pozin E. Z., Melamed V. Z., Azovtseva S. M. Design and efficiency evaluation of cutter heads of shearers. Improvement of reliability and design of mining machines : Collected papers. Moscow : Institut gornogo dela im. A. A. Skochinskogo, 1986. pp. 29-34.

14. Yuanping Cheng, Liang Wang, Hongyong Liu, Shengli Kong, Quanlin Yang et al. Definition, theory, methods, and applications of the safe and efficient simultaneous extraction of coal and gas. International Journal of Coal Science \& Technology. 2015. Vol. 2, Iss. 1. pp. 52-65.

15. Jinhua Wang, Bin Yu, Hongpu Kang, Guofa Wang, Debing Mao et al. Key technologies and equipment for a fully mechanized top-coal caving operation with a large mining height at ultrathick coal seams. International Journal of Coal Science \& Technology. 2015. Vol. 2, Iss. 2. pp. 97-161.

16. Pozin E. Z., Sovetov V. L. Optimization of operating conditions of cutter heads. Reliability and design optimization of mining machines : Collected papers. Moscow : Institut gornogo dela im. A. A. Skochinskogo, 1987. pp. 26-34

17. Naeimipour A., Rostami J., Buyuksagis I. S., Frough O. Estimation of rock strength using scratch test by a miniature disc cutter on rock cores or inside boreholes. International Journal of Rock Mechanics and Mining Sciences. 2018. Vol. 107. pp. 9-18.

18. Guofa Wang, Yihui Pang. Surrounding rock control theory and longwall mining technology innovation. International Journal of Coal Science \& Technology. 2017. Vol. 4, Iss. 4. pp. 301-309. EM 